\title{
An angiographic curiosity: Coronary artery ectasia. A review of possible aetiological factors, clinical and histopathological features and treatment
}

\author{
Mücahid Yılmaz* and Mehmet Nail Bilen \\ Elazığ Education and Research Hospital, Department of Cardiology, Turkey
}

\begin{abstract}
Coronary artery ectasia (CAE) is defined as widening of at least one coronary artery so as to be 1.5 -fold or greater than the normal coronary artery segment. Coronary artery dilation not accompanied by a significant coronary artery stenosis is defined as "isolated coronary ectasia". The CAE prevalence has been reported as $0.22-$ $5.3 \%$ in the literature. CAE most commonly involves the right coronary artery, followed by circumflex artery and the left anterior descending artery. It is considered to be a variant of coronary atherosclerosis. However, its etiology is still obscure. The vast majority of the cases are evaluated in the category of non-atherosclerosis inflammatory diseases, connective tissue diseases and congenital diseases. The clinical symptoms may include stable or unstable angina and atypical chest pain. The causes of the clinical condition include ischemia and spontaneous dissections. The main cause of ischemia and angina is impaired micro-vascular perfusion. Increased thrombogenicity developing in the ectatic segment and consequent distal embolization of thrombi are among the most important causes of impaired micro-vascular perfusion. In this manuscript, it was aimed to provide information about the etio-pathogenesis of CAE and survival, and to review the treatment approaches.
\end{abstract}

\section{Introduction}

An abnormal enlargement of one part of the coronary artery to 1.5 times more than the diameter of an adjacent normal segment is defined as coronary artery ectasia (CAE), and further enlargement is defined as coronary artery aneurysm [1]. Befeler B et al. [2] defined the enlargements up to 2 times as ectasia, whereas enlargements exceeding 2 times the normal diameter as aneurysms. Alford WC Jr et al. [3] described the diameter of the aneurysm as three times or more than the normal diameter. Tunick et al. [4] specified the angiographic characteristics of distinguishing a diffuse aneurysmal ectasia from a discrete aneurysm. The fusiform enlargements of the coronary arteries are defined as diffuse ectasia, and the saccular or spherical enlargements, which are localized abnormal dilatation of the coronary arteries, are defined as discrete aneurysm (Figures 1-4).

Markis et al. [5] divided CAE into four subgroups depending on the diffuseness of ectasia. Type 1: Diffuse ectasia in two vessels; Type 2: Diffuse ectasia in one vessel, discrete ectasia in another vessel; Type 3: Diffuse ectasia in one vessel; Type 4: Discrete ectasia in one vessel. Harikrishnan classification is a new classification proposed for CAE and is used to classify the cases that cannot be included into one of the four groups specified in Markis classification, such as diffuse ectasia in one vessel, local ectasia in two vessels or local ectasia in two or three vessels [6,7] (Table 1). Both classifications can be used to classify CAE.

\section{Epidemiology}

While the prevalence of CAE has been reported to be $5 \%$ in various angiographic series, its prevalence has been reported to be between $0.22 \%$ and $1.4 \%$ in the autopsy series [5,8-10]. The incidence of CAE was $5.3 \%$ in a study of Glagov S et al. [11] conducted on 3900 patients who were examined by using coronary angiography. Whereas, the incidence of CAE was reported to be $10 \%$ by Sharma SN et al. [12].
Coronary artery dilatation without significant coronary artery stenosis is called isolated coronary artery ectasia [5]. Hartnell et al. [8] reported that only $17 \%$ of CAE patients did not have a significant comorbid coronary artery stenosis. Swaye PS et al. [10] reported that a significant coronary stenosis was observed in $90.8 \%$ of CAE patients, and it was observed in $82 \%$ of the patients in another study conducted by Sadr-Ameli M et al. [13].

Syed M et al. [14] reported that coronary ectasia was most commonly found in the RCA and the least commonly in the LMCA. In another study, the most common involvement was observed in the RCA [10]. Yip et al. [15] also reported that ectasia was most commonly seen in the RCA, followed by the involvement of the LAD and Cx, respectively [15].

\section{Aetiopathogenesis}

Coronary artery ectasia may be congenital or acquired $[13,16-$ 19]. The associated diseases reported in its aetiology are $50 \%$ atherosclerosis, $20-30 \%$ congenital diseases, and 10-20\% inflammatory or connective tissue diseases [20]. The most common underlying condition in adults is coronary artery disease [3-5,10-12,21]. The thinning of the vascular media layer is remarkable in the pathogenesis of atherosclerosis and ectasia. A thin vascular wall and an increased wall stress result in a vicious cycle thus, a diffuse ectasia or local aneurysm develops as a result of progressive dilatation in the coronary

*Correspondence to: Mücahid Yılmaz, Elazığ Education and Research Hospital, Department of Cardiology Turkey, Tel: 905337719783; E-mail: mucahid. yilmaz@mynet.com

Key words: coronary artery ectasis, coronary artery disease, ischemia

Received: June 27, 2018; Accepted: August 06, 2018; Published: August 11, 2018 


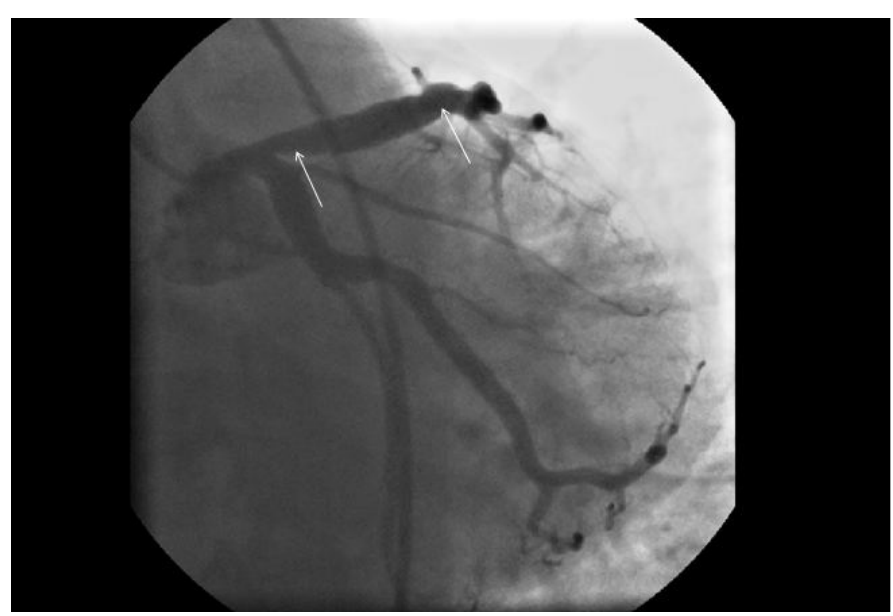

Figure 1. A fusiform ectasia in the LAD (Left anterior descending) artery, in the region between the white arrows

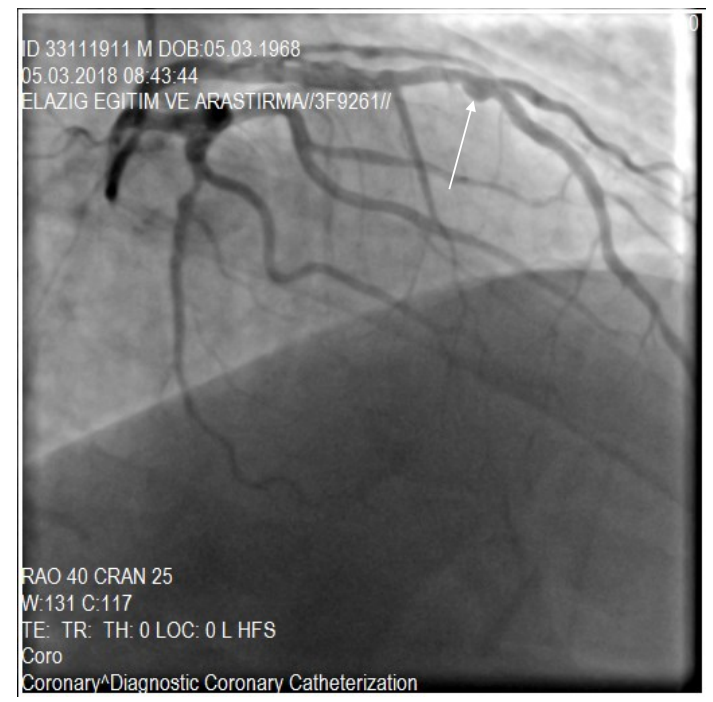

Figure 2. A saccular ectasia form in the LAD (Left anterior descending) artery, showed with the white arrow

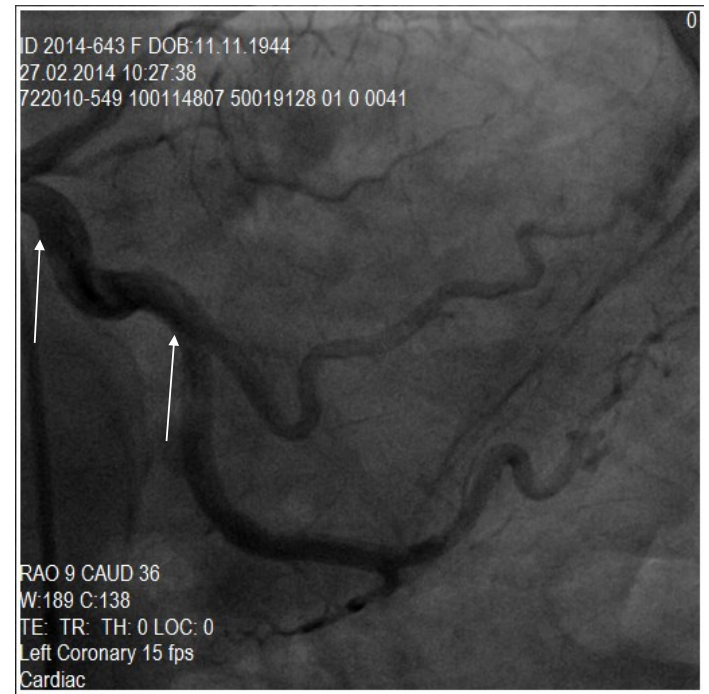

Figure 3. A fusiform ectasia in the $\mathrm{CX}$ (Circumflex) artery, in the region between the white arrows

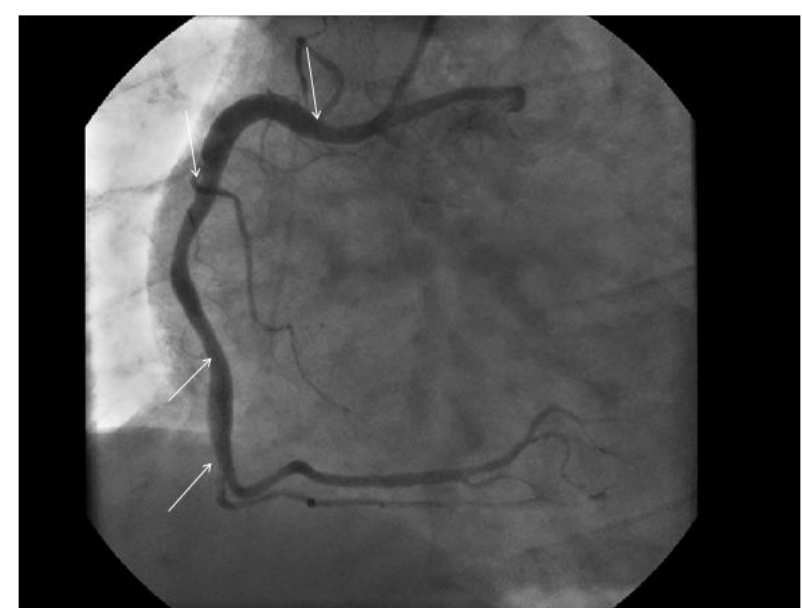

Figure 4. A fusiform ectasia in the RCA (Right coronary artery), in the region between the white arrows

Table 1. Harikrishnan et al. [7] Classification of Coronary Artery Ectasia

\begin{tabular}{|l|l|l|}
\hline Type 1 & Diffuse ectasia in two or three vessel & $\begin{array}{l}\text { A: } \text { Diffuse ectasia in three vessels } \\
\text { B: Diffuse ectasia in two vessels and a } \\
\text { localized ectasia in another vessel } \\
\text { C: } \text { Diffuse ectasia in two vessels }\end{array}$ \\
\hline Type 2 & $\begin{array}{l}\text { Diffuse ectasia in one vessel and } \\
\text { localized ectasia in other vessels }\end{array}$ & $\begin{array}{l}\text { A: } \text { Diffuse ectasia in one vessel and a } \\
\text { localized ectasia in another vessel } \\
\text { B: Diffuse ectasia in one vessel and } \\
\text { localized ectasia in other two vessels }\end{array}$ \\
\hline Type 3 & Diffuse ectasia in one vessel & $\begin{array}{l}\text { A: } \text { Localized in one vessel } \\
\text { B: } \text { Localized in two vessels } \\
\text { C: } \text { Localized in three vessels }\end{array}$ \\
\hline Type 4 & Localized or segmental ectasia &
\end{tabular}

artery [22,23]. A study of Markis et al. [5] demonstrated that the underlying histologic changes in CAE are equivalent to the changes observed in atherosclerotic lesions (generalized hyalinization, intimal and medial deterioration). It was demonstrated in another study that at first, the media underwent atrophy and secondarily, the intima was affected [24]. The ectatic process is considered to be initiated by the enzymes responsible for the elimination of extracellular matrix on the coronary artery media layer [25]. Atherosclerotic disease is a long process. Early atherosclerotic disease thickens the vascular wall without causing luminal stenosis (positive remodeling). Luminal stenosis is the last stage of atherosclerotic disease (negative remodeling). Glagov et al. [11] reported that a compensatory enlargement also began in the locations where the atherosclerotic plaque began to narrow the surface area of the human coronary artery. Although its mechanism has not been fully understood, this compensatory enlargement ceases when the volume of the plaque reaches $40 \%$ of the internal elastic lamina $[11,26]$. Degeneration of the connective tissue of the coronary artery wall, especially with proteases, leads to a positive remodeling on the coronary artery wall. CAE is considered to be an exaggerated form of this process (positive remodeling) [20]. Ge J et al. [27] obtained findings of peripheral intimal thickening in the ectatic location as a result of a study they conducted under the guidance of IVUS (IntraVascular Ultrasonography).

There are several publications arguing that there is a common mechanism since abdominal aortic aneurysm is more common in patients with coronary artery ectasia and musculo-elastic layers are damaged due to the atherosclerotic process in both cases [26,28,29]. Current studies revealed that inflammatory processes has a great role in the aetiopathogenesis of CAE similar to the aetiopathogenesis of 
abdominal aortic aneurysm [30-33]. However, Harikrishnan et al. [34] reported that the incidence of coronary ectasia was not increased in patients with peripheral artery disease and thoracoabdominal aortic aneurysm.

It is known that Ehlers-Danlos syndrome, systemic lupus erythematosus, polyarteritis nodosa, syphilis, takayasu's arteritis, kawasaki disease, scleroderma, percutaneous transluminal coronary angioplasty (PTCA), exposure to herbicide and nitrate products, bacterial and mycotic infections increase the incidence of CAE by weakening the connective tissue on the arterial media layer [20]. It was reported that, Chlamydia pneumoniae has been implicated in the pathogenesis of the ectasia by producing heat shock protein 60 which regulates matrix metalloproteinase (MMP) enzymes [35]. Enzymatic degradation of extracellular matrix of the media layer have a fundamental pathologic process [36]. Proteolytic enzymes such as cysteine proteinases (e.g. cathepsins K, L, and S) and serine proteinases (e.g. neutrophil elastase, plasminogen activators, plasmin, chymase and tryptase) also play an important role in the pathogenesis of coronary ectasia [37] . Likewise, elevated homocysteine levels may facilitate the degradation of the medial arterial layer by inducing serine proteinase activity in arterial smooth muscle cells, as well as by activating matrix metalloproteinase (MMP) [36].

2,4-dichlorophenoxyacetic acid and 2,4,5-trichlorophenoxyacetic acid, commonly used in herbicides, are acetylcholine esterase inhibitors. Prolonged exposure to these agents, chronically elevates the concentration of acetylcholine in the coronary artery interstitium. The mechanisms of 2,4-dichlorophenoxy acetic acid and 2,4,5-trichlorophenoxy acetic acid found in herbicides are probably the competitive inhibition of acetic acid and choline degradation that the last products of acetylcholine. Again, the acetylcholine esterase inhibitors in herbicides directly elevate the concentration of acetylcholine. Acetylcholine is a potent stimulator of NO (Nitric Oxide). Herbicides can locally elevate the concentration of NO. The stimulation of NO leads to a relaxation of vascular smooth muscles via guanylate cyclase and release of calcium from the endoplasmic reticulum. However, there is no consensus on whether chronic relaxation leads to coronary artery ectasia or not [38].

Sudhir et al. [39] found that patients with familial hypercholesterolemia had a higher incidence for CAE compared to patients with other coronary atherosclerosis, and that this showed a strong correlation with low HDL levels, and suggested that a disorder of lipoprotein metabolism could lead to aneurysmal CAD. Güleç et al. [40] reported that angiotensin converting enzyme gene deletion polymorphism is a potent risk factor for the development of CAE.

It has been reported that CAE was more common in males $[12,41]$. Smoking, hypertension and hyperlipidemia are common in patients with coronary artery disease and comorbid CAE [20]. There are publications indicating that there is a negative correlation between diabetes mellitus and CAE [41,42]. Diabetes mellitus primarily affecting the intima, not affecting the media layer and leading to negative remodeling, as well as an impairment in the synthesis and inhibition of NO disrupting the endothelium-dependent vasodilation has been used to explain the negative correlation between the two cases $[41,42]$. However, Keçebas et al. [43] reported that DM and CAE with coronary artery disease origin had a positive correlation, and diabetes mellitus causes the increased risk of CAE by 2.59 -fold in these patients. It is possible to say in the light of this information that the predisposing factors setting the stage for the formation of CAE could not be fully enlightened, and that the disagreements on this subject preserve continuity.

\section{Survival}

Coronary artery ectasia is mostly asymptomatic. Symptomatic cases usually emerge in the form of effort angina. However, it may also manifest itself with rest angina. Some studies reported that ectasia caused slow blood flow, thrombus formation and vasospasm in coronary arteries; and suggested that it could also lead to an ischemic heart disease without obstructive CAD, and even clinical tables that could result in myocardial infarction $[21,44]$. CAE may provide a basis for spontaneous dissection [45]. It has been reported that possible spontaneous dissection and thrombus occlusion were responsible for myocardial infarction [18-21]. It has been reported that the microembolies formed in CAE could result in ventricular arrhythmias and sudden death of cardiac origin by impairing the coronary perfusion $[10,11,13,18]$. These symptoms may also be presented in CAE cases without significant stenosis [26].

The ischemic mechanism in patients with coronary artery ectasia has not been fully understood. However, it is accepted that the leading cause of ischemia and angina is the impaired microvascular perfusion. It has been reported that a slow or turbulent flow in the dilated vessels resulted in thrombosis or ischemia at the ectatic segment, leading to embolism in the distal coronary artery [1]. Güleç et al. [46] demonstrated that the epicardial and microvascular perfusion were impaired in patients with ectasia. The same study reported that the TIMI (Thrombolysis In Myocardial Infarction) frame count was small enough to predict an impaired microvascular perfusion when comparing ectatic arteries with non-ectatic arteries [46]. An increased thrombogenicity and distal embolization in CAE have been demonstrated to be the most important cause of impaired microvascular perfusion [18-21]. The thesis arguing that some lesser-known factors leading to excessive dilatation of the epicardial arteries could cause perfusion failure in microcirculation has not been proven yet [20]. 17 of $33 \mathrm{CAE}$ patients with non-occlusive CAD were found to have a positive exercise test in a study, and it was concluded that CAE led to ischemia [47]. The coronary flow velocity was measured in another study and it was demonstrated that the flow rate decreased significantly within the aneurysm, however it was normal at the adjacent normal segment [48]. Two recent studies identified left ventricular diastolic dysfunction in patients with ectasia, who were examined by using tissue Doppler method, and it was suggested that it could originate from microvascular dysfunction and/ or ischemia $[49,50]$. A recent study conducted on patients with CAE found an impaired heart rate variability that associated with an increase in the progression of CAD and in the risk of mortality [51].

The prognosis is controversial. Swaye et al. [10] reported that they did not found a difference in mortality rate compared to the control group, regardless of whether the treatment was medical or surgical. Hartnell et al. [8] found that the yearly mortality rate was $4.6 \%$ in patients followed-up with medical therapy and $2.4 \%$ in the surgical group, and concluded that the presence of coronary ectasia did not affect the mortality rate alone. Yilmaz et al. [52] reported that the yearly mortality rate was found to be $1.5 \%$ in medically followed-up patients, $2.1 \%$ in those underwent percutaneous coronary intervention and $2.9 \%$ in those underwent aortocoronary by-pass operation, as a result of an average 34-month follow-up. The long-term prognosis of the control group and isolated CAE patients was found to be similar in a number of retrospective records [53]. Markis et al. [5] reported that the short-term prognosis was the same as patients with three-vessel disease followed 
up with medical therapy, and that a yearly mortality rate was $15 \%$. The high mortality rate in this study was attributed to the large number of patients with three-vessel disease.

\section{Diagnosis}

$\mathrm{X}$-ray coronary angiography is the main diagnostic technique for the identification of coronary artery ectasia. Angiographic signs of turbulent and stagnant flow include delayed antegrade dye filling, a segmental back flow phenomenon and local deposition of dye in the dilated coronary segment [54].

Intra vascular ultra sound (IVUS) is the best tool for assessing luminal size and determining arterial wall changes. IVUS correctly differentiates true from false aneurysms caused by plaque rupture. Emptied plaque cavities may appear angiographically as CAE and the distinction is of clinical importance, as false aneurysms may lead to acute coronary syndromes [55].

Coronary artery computed tomography (CACT) is another noninvasive modality used to diagnose CAE [56]. Contrast attenuation measurements with CACT correlated well with the flow alterations assessed with classic X-ray coronary angiography. However, CACT cannot be suggested as a technique of choice for patients' follow-up due to high radiation doses [57].

The correct follow-up of ectatic vessels is hampered by the need for repeated angiograms. Three-dimensional, non-contrast enhanced, freebreathing coronary magnetic resonance angiography (MRA) facilitates visualization of the vast majority of the proximal and middle segments of the coronary arteries [58]. It has proposed as a valuable tool for patients who present with severe left ventricular systolic dysfunction, where the underlying disease is either severe multi-vessel coronary artery disease or nonischemic cardiomyopathy. Some authors reported that, coronary MRA is equal to X-ray coronary angiography with the additional advantage of being a non-invasive technique and MRA can also be applied alone or in combination with inflammation or viability study in the evaluation of Kawasaki and other autoimmune diseases [59-62]. Compared with computed tomography and X-ray coronary angiography, magnetic resonance angiography has the advantage of requiring no exposure to radiation or injection of a contrast agent [57].

\section{Treatment}

The treatment of CAE cases is not clearly known. There is no certain treatment approach in CAE without severe comorbid coronary artery disease. The treatment of CAE patients with comorbid coronary artery disease is similar to that of patients with only coronary artery disease [63]. However, the treatment varies depending on comorbid coronary artery disease.

Platelet Aggregation Inhibitors: Thrombocyte inhibitors are used prophylactically in order to prevent ischemic syndromes associated with thrombus formation and microembolism. Although anticoagulation with warfarin is widely used, no therapeutic superiority to ASA (acetyl salicylic acid) could be demonstrated [64]. The studies in which patients with coronary artery ectasia were followed up for a long-term suggest that the warfarin therapy was not really necessary since no new infarct and no death was observed in patients with only ectasia, and no difference was found between CAE patients with comorbid coronary stenosis and CAD patients without comorbid ectasia in terms of unstable angina, MI and death [16,45]. Although the role of combined antithrombotic therapy with adenosine diphosphate inhibitors (ticlopidine and clopidogrel) has not yet been evaluated in prospective randomized studies, the use of these agents in patients who had a coronary event while using ASA or in patients who cannot take ASA is accepted in the literature [26].

Beta Blockers: Beta blockers have been demonstrated to prevent the myocardial ischemia, especially in CAE patients with comorbid ischemia [65].

Nitrates: Since coronary artery ectasia increases effort-related ischemia, it has been reported that the use nitroglycerin should be avoided in these patients [21].

Because of the common association with coronary artery disease, preventive and therapeutic approaches intended for the risk factors of CAD should be targeted. Both pharmacological and interventional methods can be used in the case of arterial thrombotic occlusion [66]. For fear of technical difficulties and complications, coronary artery by-pass grafting is preferred for revascularization rather than PCI (Percutaneous coronary intervension), but in some cases PCI can be applied successfully (Figures 4-7).

On the other hand, this situation isn't often seen. Likewise,

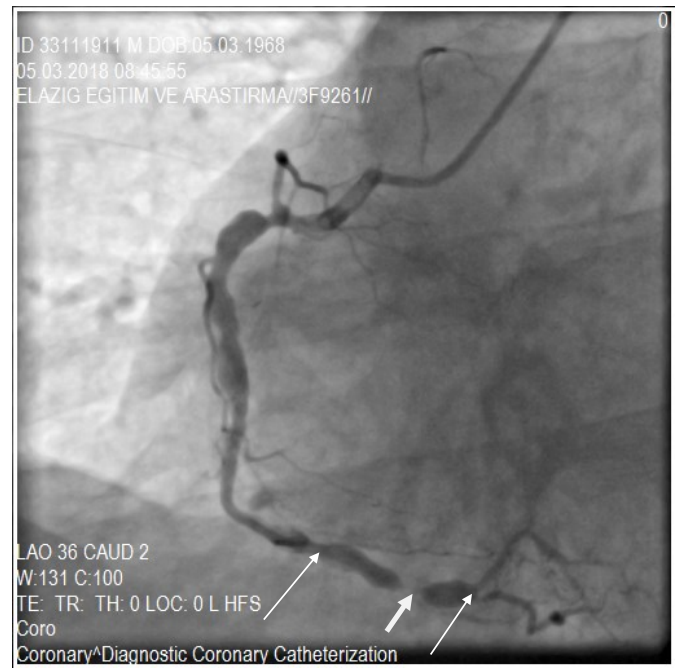

Figure 5. A fusiform ectasia with stenotic lesion in the distal segment of RCA (right coronary artery), in the region between the white arrows. Stenosis showed with thick-white arrow

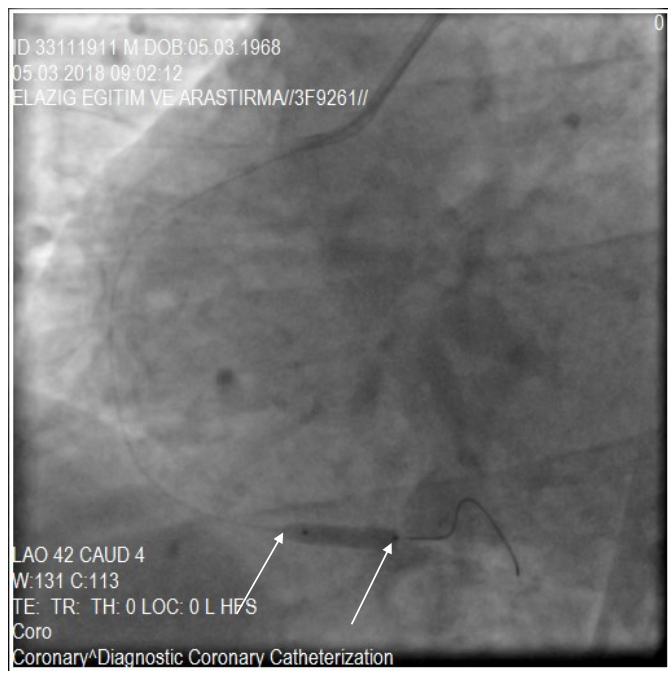

Figure 6. PCI application to the distal segment of the RCA 


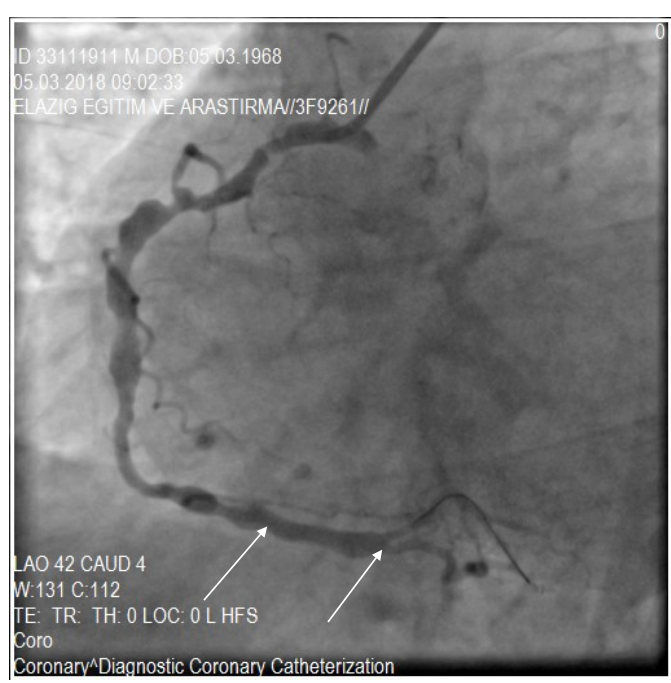

Figure 7. After PCI of the stenotic lesion that located in the region of fusiform ectasia, in the distal segment of RCA

Cokkinos et al. [67] found that the frequency of using percutaneous transluminal coronary angioplasty was three times greater $(17.4 \%$ vs. $5.8 \%)$ in CAD patients without comorbid ectasia compared to CAD patients with ectasia.

\section{Conclusion}

CAE is an uncommon coronary anomaly. It is generally accepted to be a different form of CAD and an exaggerated form of positive remodeling process. Although CAE may be asymptomatic in cases where there is no comorbid obstructive CAD, it may sometimes show up with coronary ischemia signs. Reduced coronary flow reserve associated with microvascular dysfunction has been demonstrated to be responsible for exercise-induced ischemia in cases where have not stenotic CAD. There is no consensus in the literature in terms of approach to coronary artery ectasia. Nevertheless, given the common association with atherosclerosis, targeting the risk factors for CAD and the use of antihypertensive, anti-coagulant and beta-blocker agents are recommended for the prevention and treatment of CAE.

\section{References}

1. Falsetti HL, Carrol RJ (1976) Coronary artery aneurysm. A review of the literature with a report of 11 new cases. Chest 69: 630-636. [Crossref]

2. Befeler B, Aranda MJ, Embi A, Mullin FL, El-Sherif N, et al. (1977) Coronary artery aneurysms: study of the etiology, clinical course and effect on left ventricular function and prognosis. Am J Med 62: 597-607. [Crossref]

3. Alford WC Jr, Stoney WS, Burrus GR, Frist RA, Thomas CS Jr (1976) Recognition and operative management of patients with arteriosclerotic coronary artery aneurysms. Ann Thorac Surg 22: 317-321. [Crossref]

4. Tunick PA, Slater J, Kronzon I, Glassman E (1990) Discrete atherosclerotic coronary artery aneurysms: a study of 20 patients. $J$ Am Coll Cardiol 15: 279-282. [Crossref]

5. Markis JE, Joffe CD, Cohn PF, Feen DJ, Herman MV, et al. (1976) Clinical significance of coronary arterial ectasia. Am J Cardiol 37: 217-222. [Crossref]

6. Akcay S, Turker Y, Ozaydin M, Yucel H, Altinbas A (2010) Frequency of coronary artery ectasia among patients undergoing cardiac catheterization. Anatol J Cardiol 10 191.

7. Harikrishnan S, Krishnakumar N, Jaganmohan T (2007) Coronary Artery Ectasia-Is it Time for Reappraisal? Clin Cardiol 30: 536. [Crossref]

8. Hartnell GG, Parnell BM, Pridie RB (1985) Coronary artery ectasia. Its prevalence and clinical significance in 4993 patients. Br Heart J 54: 392-395. [Crossref]

9. Oliveros RA, Falsetti HL, Carroll RJ, Heinle RA, Ryan GF (1974) Atherosclerotic coronary artery aneurysm. Report of five cases and review of literature. Arch Intern Med 134: 1072-1076. [Crossref]

10. Swaye PS, Fisher LD, Litwin P, Vignola PA, Judkins MP, et al. (1983) Aneurysmal coronary artery disease. Circulation 67: 134-138. [Crossref]

11. Glagov S, Weisenberg E, Zarins CK, Stankunavicius R, Kolettis GJ (1987) Compensatory enlargement of human atherosclerotic coronary arteries. $N$ Engl J Med 316: 1371-1375. [Crossref]

12. Sharma SN, Kaul U, Sharma S, Wasir HS, Manchanda SC, et al. (1990) Coronary arteriographic profile in young and old Indian patients with ischaemic heart disease: a comparative study. Indian Heart J 42: 365-369. [Crossref]

13. Sadr-Ameli M, Sharifi M. The natural history of ectatic coronary artery disease. Iranian Heart J 2001; 2: 12-16.

14. Syed M, Lesch M (1997) Coronary artery aneurysm: a review. Prog Cardiovasc Dis 40: 77-84. [Crossref]

15. Yip HK, Chen MC, Wu CJ, Hang CL, Hsieh KY, et al. Clinical features and outcome of coronary artery aneurysm in patients with acute myocardial infarction undergoing a primary percutaneous coronary intervention. Cardiology 2002; 98: 132-40. [Crossref]

16. Demopoulos VP, Olympios CD, Fakiolas CN, Pissimissis EG, Economides NM, et al (1997) The natural history of aneurysmal coronary artery disease. Heart 78: 136-141. [Crossref]

17. Rath S, Har-Zahav Y, Battler A, Agranat O, Rotstein Z, et al. (1985) Fate of nonobstructive aneurysmatic coronary artery disease; angiographic and clinical follow up report. Am Heart J 109: 785-791. [Crossref]

18. Mattern AL, Baker WP, McHale JJ, Lee DE (1972) Congenital coronary aneurysms with angina pectoris and myocardial infarction treated with saphenous vein bypass graft. Am J Cardiol 30: 906-909. [Crossref]

19. Frithz G, Cullhed I, Bjork L (1968) Congenital localized coronary artery aneurysm without fistula. Report of a preoperatively diagnosed case. Am Heart J 76: 674-679. [Crossref]

20. Türkmen M, Bitigen A, Esen AM (2006) Coronary Artery Ectasia. J Med Sci 26: 68-72.

21. Kruger D, Stierle U, Herrmann G, Simon R, Sheikhzadeh A (1999) Exercise-induced myocardial ischemia in isolated coronary artery ectasias and aneurysms "dilated coronopathy". J Am Coll Cardiol 34: 1461-1470. [Crossref]

22. Isner JM, Donaldson RF, Fortin AH, Tischler A, Clarke RH (1986) Attenuation of the media of coronary arteries in advanced atherosclerosis. Am J Cardiol 58: 937-939. [Crossref]

23. Gussenhoven EJ, Frietman PA, The SH, van Suylen RJ, van Egmond FC, et al. (1991) Assessment of medial thinning in atherosclerosis by intravascular ultrasound. Am J Cardiol 68: 1625-1632. [Crossref]

24. Berkoff HA, Rowe GG (1975) Atherosclerotic ulcerative disease and associated aneurysms of the coronary arteries. Am J Cardiol 90: 153-158.

25. Antoniadis AP, Chatzizisis YS, Giannoglou GD (2008) Pathogenetic mechanisms of coronary ectasia. Int J Cardiol 130: 335-343. [Crossref]

26. Boztosun B, Günes Y, Kirma C (2005) Coronary Artery Ectasia. Arch Turk Soc Cardiol 33: 356-359.

27. Ge J, Erbel R, Zamorano J, Koch L, Kearney P, et al. (1993) Coronary artery remodelling in atherosclerotic disease: An intravascular ultrasonic study in vivo. Coron Artery Dis 4: 981-986. [Crossref]

28. Starc R, Janezic A, Cijan A (1991) Angiographic evidence of coronary artery ectasia: our experience. Cor Vasa 33: 288-293. [Crossref]

29. DAOUD AS, PANKIN D, TULGAN H, FLORENTIN RA (1963) Aneurysms of the coronary artery. Report of ten cases and review of literature. Am J Cardiol 11: 228-237. [Crossref]

30. Tokgozoglu L, Ergene O, Kinay O, Nazli C, Hascelik G, et al. (2004) Plasma interleukin-6 levels are increased in coronary artery ectasia. Acta Cardiol 59: 515-519. [Crossref]

31. Kundi H, Gok M, Kiziltunc E, Cetin M, Cicekcioglu H, et al. (2015) Relation Between Monocyte to High-Density Lipoprotein Cholesterol Ratio With Presence and Severity of Isolated Coronary Artery Ectasia. Am J Cardiol 116: 1685-1689. [Crossref]

32. Mehmet Demir, Serdar Keceoglu, Mehmet Melek (2013) The Relationship Between Plasma Eosinophil Count and Coronary Artery Ectasia. Cardiol Res 4: 159-164. [Crossref]

33. Yilmaz M, Korkmaz H, Bilen MN, Uku Ö, Kurtoglu E (2016) Could neutrophil/ 
lymphocyte ratio be an indicator of coronary artery disease, coronary artery ectasia and coronary slow flow? J Int Med Res 44: 1443-1453. [Crossref]

34. Harikrishnan S, Sunder KR, Tharakan J, Titus T, Bhat A, et al. (2000) Coronary artery ectasia: angiographic, clinical profile and follow-up. Indian Heart $J$ 52: 547-553. [Crossref]

35. Kol A, Sukhova GK, Lichtman AH, Libby P (1998) Chlamydial heat shock protein 60 localizes in human atheroma and regulates macrophage tumor necrosis factor-alpha and matrix metalloproteinase expression. Circulation 98: 300-307. [Crossref]

36. Antoniadis AP, Chatzizisis YS, Giannoglou GD (2008) Pathogenetic mechanisms of coronary ectasia. Int $J$ Cardiol 130: 335-343. [Crossref]

37. Liu J, Sukhova GK, Yang JT, Sun J, Ma L, et al. (2006) Cathepsin L expression and regulation in human abdominal aortic aneurysm, atherosclerosis, and vascular cells. Atherosclerosis 184: 302-311. [Crossref]

38. Sorrell VL, Davis MJ, Bove AA (1996) Origins of coronary artery ectasia. Lancet 347: 136-137. [Crossref]

39. Sudhir K, Ports TA, Amidon TM, Goldberger JJ, Bhushan V, et al. (1995) Increased prevalence of coronary ectasia in heterozygous familial hypercholesterolemia. Circulation 91: 1375-1380. [Crossref]

40. Gülec S, Aras O, Atmaca Y, Akyürek O, Hanson NQ, et al. (2003) Deletion polymorphism of the angiotensin I converting enzyme gene is a potent risk factor for coronary artery ectasia. Heart $89:$ 213-214. [Crossref]

41. Pinar Bermúdez E, López Palop R, Lozano Martínez-Luengas I, Cortés Sánchez R, Carrillo Sáez P, et al. (2003) [Coronary ectasia: prevalence, and clinical and angiographic characteristics]. Rev Esp Cardiol 56: 473-479. [Crossref]

42. Androulakis AE, Andrikopoulos GK, Kartalis AN, Stougiannos PN, Katsaros AA, et al. (2004) Relation of coronary artery ectasia to diabetes mellitus. Am J Cardiol 93: 1165-1167. [Crossref]

43. Kecebas M, Besli F, Alisir MF (2015) The Relationship Between Atherosclerotic Risk Factors and Coronary Artery Disease in Coronary Artery Ectasia. Duzce Medical Journal 17: 1-4.

44. Papadakis MC, Manginas A, Cotileas P, Demopoulos V, Voudris V, et al. (2001) Documentation of slow coronary flow by the TIMI frame count in patients with coronary ectasia. Am J Cardiol 88: 1030-1032. [Crossref]

45. Farto e Abreu P, Mesquita A, Silva JA, Seabra-Gomes R (1993) Coronary artery ectasia: clinical and angiographic characteristics and prognosis. Rev Port Cardiol 12: 305-310. [Crossref]

46. Gulec S, Atmaca Y, Kilickap M, Akyürek O, Aras O, et al. (2003) Angiographic assessment of myocardial perfusion in patients with isolated coronary artery ectasia. Am J Cardiol 91: 996-999, A7. [Crossref]

47. Sayin T, Doven O, Berkalp B, Akyürek O, Gulec S, Oral D (2001) Exercise-induced myocardial ischemia in patients with coronary artery ectasia without obstructive coronary artery disease. Int J Cardiol 78: 143-149. [Crossref]

48. Hamaoka K, Onouchi Z, Kamiya Y, Sakata K (1998) Evaluation of coronary flow velocity dynamics and flow reserve in patients with Kawasaki disease by means of a Doppler guide wire. J Am Coll Cardiol 31: 833-840. [Crossref]

49. Saglam M, Barutçu I, Karakaya O, Esen A.M, Akgun T, et al. (2008) Assessment of left ventricular functions in patients with isolated coronary artery ectasia by conventional and tissue Doppler imaging. Angiology 59: 306-311. [Crossref]
50. Tuzun N, Tanriverdi H, Evrengul H, Kuru DS, Ergene AO (2007) Aortic elastic properties in patients with coronary artery ectasia. Circ J 71: 506-510. [Crossref]

51. Turker Y, Ozaydin M, Yucel H (2010) Heart rate variability and heart rate recovery in patients with coronary artery ectasia. Coron Artery Dis 21: 8-12. [Crossref]

52. Yilmaz H, Sayar N, Yilmaz M, Tangürek B, Cakmak N, et al. (2008) [Coronary artery ectasia: clinical and angiographical evaluation]. Turk Kardiyol Dern Ars 36: 530-535. [Crossref]

53. Demopoulos V, Dalampiras P, Sifaki M, Olympos C, Foussas S, et al. (1999) Isolated coronary artery ectasia does not have a benign long-term prognosis. $\mathrm{J} \mathrm{Am} \mathrm{Coll} \mathrm{Cardiol}$ 33: $1128-1140$

54. Mavrogeni S (2010) Coronary artery ectasia: from diagnosis to treatment. Hellenic $J$ Cardiol 51: 158-163. [Crossref]

55. Sanidas EA, Vavuranakis M, Papaioannou TG, Kakadiaris IA, Carlier S, et al. (2008) Study of atheromatous plaque using intravascular ultrasound. Hellenic J Cardiol 49: 415-421. [Crossref]

56. Díaz-Zamudio M, Bacilio-Pérez U, Herrera-Zarza MC, Meave-González A Alexanderson-Rosas E, et al. (2009) Coronary artery aneurysms and ectasia: role of coronary CT angiography. Radiographics 29: 1939-1354. [Crossref]

57. Magrogeni S (2018) Coronary artery ectasia: diagnosis and treatment. Available at: https://www.escardio.org/.../Coronary-artery-ectasia-diagnos.

58. Mavrogeni S, Markousis-Mavrogenis G, Kolovou G (2014) Contribution of cardiovascular magnetic resonance in the evaluation of coronary arteries. World $J$ Cardiol 6: 1060-1066. [Crossref]

59. Mavrogeni SI, Manginas A, Papadakis E, Foussas S, Douskou M, et al. (2004) Correlation between magnetic resonance angiography (MRA) and quantitative coronary angiography (QCA) in ectatic coronary vessels. J Cardiovasc Magn Reson 6: 17-23. [Crossref]

60. Mavrogeni SI, Manginas A, Papadakis E, Douskou M, Cokkinos D, et al. (2005) Coronary flow evaluation by TIMI frame count and magnetic resonance flow velocity in patients with coronary artery ectasia. J Cardiovasc Magn Reson 7: 545-550. [Crossref]

61. Mavrogeni S, Papadopoulos G, Karanasios E, Georgakopoulos D, Manoussakis MN (2009) Microscopic polyangiitis and Kawasaki disease without overt clinica cardiovascular manifestations and with abnormal cardiovascular magnetic resonance findings. Int $J$ Cardiol.

62. Mavrogeni S, Papadopoulos G, Douskou M, Kaklis S, Seimenis I, et al. (2006) Magnetic resonance angiography function and viability evaluation in patients with Kawasaki disease. J Cardiovasc Magn Reson 8: 493-498. [Crossref]

63. Yetkin E, Waltenberger J (2007) Novel insights into an old controversy: is coronary artery ectasia a variant of coronary atherosclerosis? Clin Res Cardiol 96: 331-339. [Crossref]

64. Perlman PE, Ridgeway NA (1989) Thrombosis and anticoagulation therapy in coronary ectasia. Clin Cardiol 12: 541-542. [Crossref]

65. Jackson G, Atkinson L, Oram S (1977) Improvement of myocardial metabolism in coronary arterial disease by beta-blockade. Br Heart J 39: 829-833. [Crossref]

66. Rab ST, Smith DW, Alimurung BN, Rab R, King SB 3rd (1990) Thrombolytic therapy in coronary ectasia and acute myocardial infarction. Am Heart $J$ 119: 955-957. [Crossref]

67. Cokkinos DV, Demopoulos VP, Voudris V (1999) Coronary artery ectasia: aspects of fitness to fly. Eur Heart $J$.

Copyright: (C2018 Y1lmaz M. This is an open-access article distributed under the terms of the Creative Commons Attribution License, which permits unrestricted use, distribution, and reproduction in any medium, provided the original author and source are credited. 